\title{
FLORA DA BA DE PELTOGYNE VOGEL
}

\author{
Fernanda Gomes Silva ${ }^{1}$; Isys M. Souza ${ }^{2}$; Ligia S. Funch ${ }^{3}$ \\ 1. Bolsista PIBIC/CNPq, Graduando em Licenciatura em Ciências Biológicas, Universidade Estadual de Feira de \\ Santana, e-mail: fernandagomes0104@gmail.com \\ 2. Participante do projeto ou núcleo tal, DCBIO, Universidade Estadual de Feira de Santana, e-mail: \\ isys.souza@gmail.com \\ 3. Orientador, DCBIO, Universidade Estadual de Feira de Santana, e-mail: ligiafunch@yahoo.com
}

PALAVRAS-CHAVE: Fabaceae; taxonomia; pau roxo.

\section{INTRODUÇÃO}

Peltogyne é um gênero de Leguminosae amplamente distribuído na região neotropical, ocorrendo do México ao sudeste brasileiro (Silva, 1976). O gênero é caracterizado pelo hábito arbóreo, folhas bifolioladas, flores brancas, ovário estipitado e legumes orbiculares a triangulares, comprimidos, monospérmicos (Bentham, 1870; Silva, 1976). Bentham (1870) descreveu sete espécies para o Brasil; Silva (1976), na revisão, apresentou 23 espécies; e Lima \& Cordula (2015) indicam 25 espécies, sendo seis referidas para a Bahia. Incongruências na taxonomia de Peltogyne, bem como a quantidade de material sem identificação nos herbários, apontam para a necessidade de estudos mais apurados. Aqui é apresentada a flora de Peltogyne para a Bahia.

\section{MATERIAL E MÉTODOS}

O levantamento das espécies, descrições e chave de identificação foram realizados a partir da análise dos materiais disponíveis nas bases de dados do CRIA, REFLORA e HUEFS. A identificação das espécies baseou-se em consultas às obras príncipes e comparação com os materiais tipo. Mapas de distribuição foram elaborados utilizando ferramenta do projeto Flora da Bahia (http://www2.uefs.br/floradabahia/Default.asp).

\section{RESULTADOS E/OU DISCUSSÃO}

Peltogyne é amplamente distribuído no Brasil (Lima \& Cordula, 2015). O gênero tem afinidade com Guibourtia Benn. e Hymenea L., com os quais partilha as folhas bifolioladas, folíolos assimétricos e pontuações translúcidas. A análise das espécies para a Bahia indica que características foliares, como tamanho, largura, ápice e base dos folíolos, são bons descritores taxonômicos (Figura 1). 

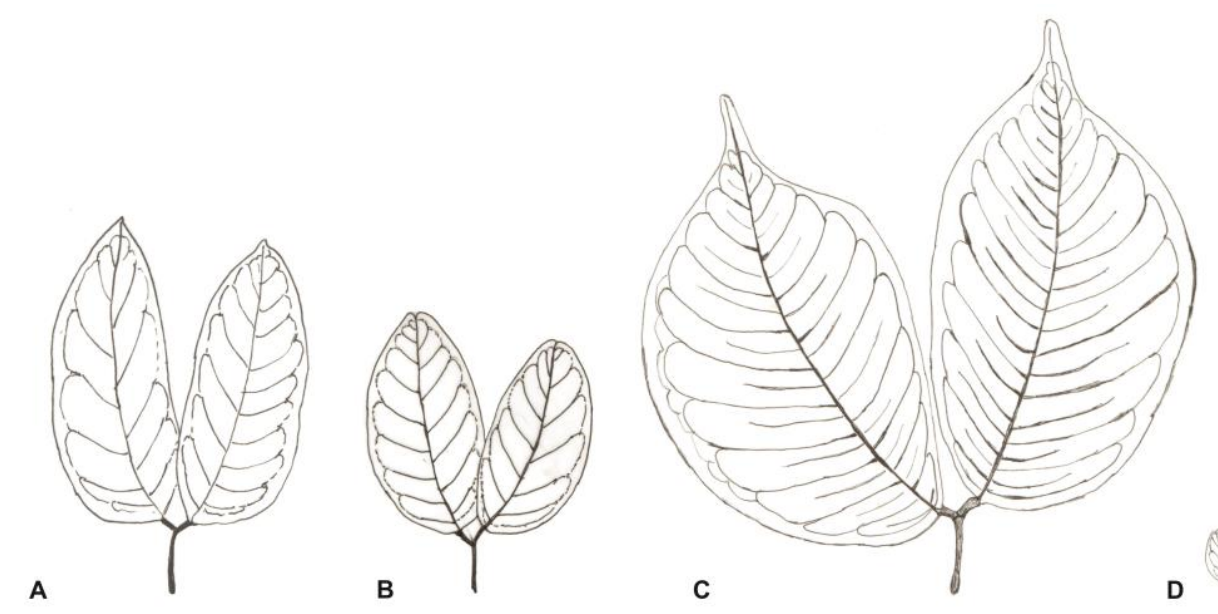

Figura 1: Folhas das espécies de Peltogyne para BA. A - P. angustiflora (H.C. de Lima, 6900); B - P. chrysopis (A. Amorim, 1382); C - P. confertiflora (D.C. Cardoso, 32); D - P. pauciflora (L.P. de Queiroz, 4819).

\section{Chave para as espécies e variedades}

1. Inflorescência laxa; frutos orbiculares, alados 3. P. chrysopis

1'. Inflorescência congesta; frutos oblongos, hemi-orbiculares, triangulares, não-alados

2. Folíolos pequenos (2,3-4,2 cm compr.); flores pequenas (0,3-0,7 cm compr.); frutos hemi-orbiculares 4. P. pauciflora 2'. Folíolos grandes (igual ou maiores que 5,2 cm compr.); flores grandes (maiores que $0,7 \mathrm{~cm}$ compr.); frutos triangulares

3. Folíolos com lado externo da base leve a fortemente arredondado; panícula mais longa que a folha adjacente

2. P. confertiflora

3'. Folíolos com lado externo da base truncado; panícula mais curta que a folha adjacente

1. $P$. angustiflora
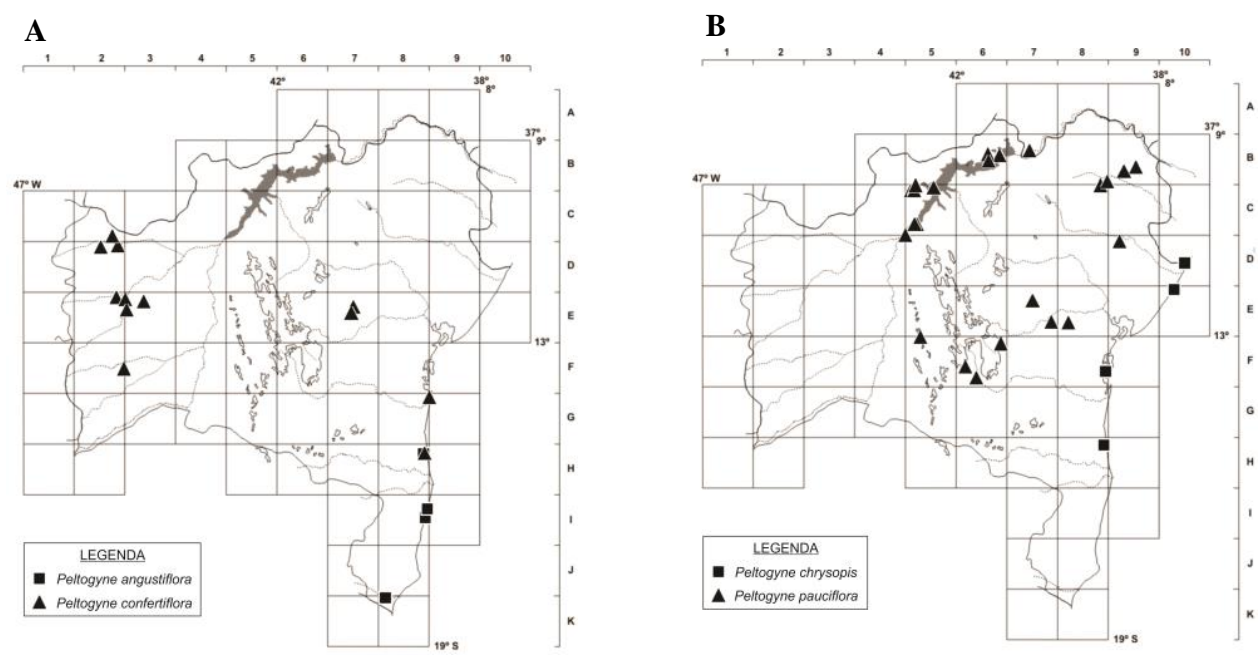

Figura 2: Peltogyne na Bahia. A - P. angustiflora e P. confertiflora; B - P. chrysopis e P. pauciflora. 
Peltogyne angustiflora Ducke, Arch. Jard. Bot. Rio de Janeiro 4: 49. 1925.

Árvores 18-25 m alt. Pecíolo 1,9-2,7 cm compr.; peciólulo 0,3-0,5 cm compr. Folíolos 6,0-11,0 × 2,7-5,0 cm, levemente falcados, elípticos, ápice agudo a aculeado, base ligeiramente oblíqua, lado interno agudo, lado externo truncado. Panícula congesta, mais curta que a folha adjacente. Flor 2,1-2,2 cm compr.; sépalas 0,6-0,7 cm compr.; pétalas 0,2-0,5 cm compr., elípticas; ovário $0,2-0,3 \times 0,1-0,2 \mathrm{~cm}$, subtriangular, glabro. Fruto 4,0-4,9 × 2,1-2,6 cm, deiscente, lenhoso, triangular, não-alado (Figuras 1A e 2A).

Espécie das matas costeiras do Nordeste e Sudeste do Brasil (Lima \& Cordula, 2015). $\mathrm{Na}$ Bahia, ocorre no litoral sul. Peltogyne angustiflora, conhecida popularmente como "roxinho", foi referida algumas vezes erroneamente como P. angustifolia (Silva, 1976). A espécie é comumente confundida com $P$. confertiflora, da qual difere pelos folíolos estreitos, base truncada externamente e inflorescência mais curta que a folha adjacente.

Peltogyne confertiflora (Mart. ex Hayne) Benth., Fl. Bras. 15(2): 232. 1870.

Árvores ou arbustos 1,5-15 m alt. Pecíolo 1,4-3,0cm; compr.; peciólulo 0,2-0,4 cm compr. Folíolos 5,2-13,0 × 2,7-7,5 cm, não-falcados a levemente falcados, elípticos, ápice agudo, aculeado, arredondado, base oblíqua, lado interno agudo, lado externo leve a fortemente arredondado. Panícula congesta, mais longa que a folha adjacente. Flor 1,2-1,7 cm compr.; sépalas 0,8-0,9 cm compr.; pétalas 0,9-1,0 cm compr., espatuladas; ovário $0,3 \times 0,4-0,2 \mathrm{~cm}$, subtriangular, glabro. Fruto 3,5-5,0× 2,6-3,1 cm, deiscente, não-lenhoso, triangular, não-alado (Figuras 1C e 2A).

Espécie de ampla distribuição, ocorrendo no Norte, Nordeste, Centro-Oeste e Sudeste do Brasil (Lima \& Cordula, 2015). Na Bahia, ocorre ao Norte, Oeste e ao Centro. Conhecida popularmente como "jatobá roxo" ou "pau roxo" (Silva, 1976), é confundida com P. angustiflora, diferindo nos folíolos e inflorescência. Quanto as demais, difere pelas flores grandes e frutos triangulares.

Peltogyne chrysopis Ducke, Arch. Jard. Bot. Rio de Janeiro 4: 49. 1925.

Árvore 10-25 m alt. Pecíolo 1,3-1,8 cm compr.; peciólulo 0,5-0,8 cm compr. Folíolos 6-10(-12,6) × 4-6,5(-7) cm, não-falcados, largo-elípticos, ápice obtuso, arredondado, emarginado, base oblíqua, lado interno cuneado, lado externo truncado. Panícula laxa, mais longa que a folha adjacente. Flor $1,0-1,1 \mathrm{~cm}$ compr.; sépalas $0,3-0,5 \mathrm{~cm}$ compr.; 
pétalas $0,3-0,2 \mathrm{~cm}$, elípticas; ovário $0,3-0,5 \times 0,2-0,3 \mathrm{~cm}$, orbicular, pubescente. Fruto 2,5-2,6 × 2,0-2,4 cm, deiscente, não-lenhoso, orbicular, alado (Figuras 1B e 2B).

Espécie endêmica da floresta atlântica na Bahia (Lima \& Cordula 2015), pode ocorrer simpatricamente com $P$. angustiflora e $P$. confertiflora, diferindo pela inflorescência laxa, folíolos largo-elípticos, lado interno da base cuneado e externo truncado.

Peltogyne pauciflora Benth., Fl. Bras. 15(2): 234. 1870

Árvores ou arbustos 1,0-8,0 m alt. Pecíolo 0,3-0,5 cm compr.; peciólulo 0,1-0,2 cm compr. Folíolos 2,3-4,2 × 1,4-1,9 cm, não-falcados a levemente falcados, elípticos, ápice agudo, obtuso, arredondado, retuso, base oblíqua, lado interno agudo, lado externo truncado a levemente arredondado. Panícula congesta, mais curta a mais longa que a folha adjacente. Flor 0,3-0,7 cm compr.; sépalas 0,2-0,4 cm compr.; pétalas 0,2-0,3 cm, elípticas; ovário 0,2 × 0,1 cm, hemi-orbicular, glabro a pubescente. Fruto 2,3-3,4 $\times$ 1,5-3,0 cm, deiscente, não-lenhoso a lenhoso, oblongo a hemi-orbicular, não-alado (Figuras 1D e 2B).

Espécie registrada para o Nordeste e Sudeste do Brasil (Lima \& Cordula, 2015). Amplamente distribuída na Bahia, a espécie, sinonimizada com P. glaziovii (Taub.) Dwyer por Silva (1976), apresenta grande variação morfológica, o que levanta a hipótese de sinonimização indevida. A espécie pode ocorrer simpatricamente com $P$. confertiflora, diferindo nas folhas, inflorescências e flores pequenas, e forma dos frutos.

\section{CONSIDERAÇÕES FINAIS}

O presente estudo confirma a ocorrência de quatro espécies de Peltogyne para a Bahia e levanta a hipótese de sinonimização indevida entre $P$. glaziovii e $P$. pauciflora.

\section{REFERÊNCIAS}

BENTHAM, G. 1870. Leguminosae II: Swartzieae et Caesalpinieae. In: Martius, C.F.P. (org.), Eichler, A.W. \& Urban, I. Flora Brasiliensis, v. 15, n. 2, p. 234-237.

LIMA, H.C.; CORDULA, E. 2015. Peltogyne. In: Lista de Espécies da Flora do Brasil. Disponível em: <http://floradobrasil.jbrj.gov.br/jabot/floradobrasil/FB83557>.

SILVA, M.F. 1976. Revisão taxonômica do gênero Peltogyne Vog. (Leguminosae Caesalpinioideae). Acta Amazônica 1: 1-61. 